\title{
Contextos de currículo integrado: contribuições para ler o mundo
}

\author{
Maria Aparecida Lucca Paranhos ${ }^{1}$ \\ Claudia Eliane Ilgenfritz Toso ${ }^{2}$ \\ Maristela Maria de Moraes ${ }^{3}$
}

\begin{abstract}
Resumo
Este estudo objetiva analisar uma proposta de Currículo Integrado em um contexto de ensino e aprendizagem com vistas à ampliação da formação histórico-cultural dos alunos. Entende-se que a escola e o currículo podem ser instrumentos de controle social e a composição deste currículo, com elementos da cultura próxima ao aluno, mediada pela literatura e teatro é uma ação que favorece o processo de humanização, socialização e formação de sujeitos autônomos. Os conhecimentos de diferentes componentes curriculares dão suporte para resolver problemas concretos e complexos que exigem compreender fenômenos sob diferentes olhares. Nesse contexto, intensificou-se o contato com textos literários que abordam problemáticas locais, numa relação com o universal. Propiciou-se a apreciação da arte do teatro reconhecendo tais linguagens como mediadoras do conhecimento da história local. Compõem o corpus dessa pesquisa os dados de perguntas respondidas por alunos dos 3 o e 4o anos do curso Técnico em Agropecuária do Instituto Federal de Ciência Educação e Tecnologia Farroupilha do Campus Santo Augusto. Trata-se de uma pesquisa de caráter qualitativo. Foram propostas questões sobre aspectos histórico-sociais do espaço rural da região para que os alunos argumentassem a respeito. Fez-se a análise discursiva dessas escritas, com base em Morais \& Galliazzi (2012). Os grupos leram, analisaram e discutiram obras da literatura rio-grandense, assistiram ao espetáculo teatral "Quem faz gemer a terra" e foram provocados a escrever e debater a respeito. Retomaram-se, então, as questões propostas no início da pesquisa, a fim de analisar se os sujeitos reconstruíram as visões sobre os aspectos histórico-culturais locais. Evidencia-se que os alunos se apropriaram de informações, repensaram questões culturais e ampliaram de forma considerável as competências em leitura e escrita.
\end{abstract}

Palavras-Chave: Leitura de mundo. Currículo Integrado. Formação Histórico-Cultural.

\section{Abstract}

This study aims to analyze a proposed integrated curriculum in a context of teaching and learning in order to expand the historical and cultural background of the students. It is understood that the school and the curriculum can be instruments of social control and the composition of the curriculum with elements of the next culture to the student, mediated by literature and theater is an action that favors the process of humanization, socialization and formation of autonomous individuals. The knowledge of different curriculum

${ }^{1}$ Mestre em Letras- Área de Concentração em Estudos Linguísticos pela Universidade Federal de Santa Maria UFSM. Master per Formatori Docenti di Italiano come L2 - Università Ca' Foscari - Veneza - Itália Especialista em Leitura e Metodologia do Texto Literário Infantil e Infanto-Juvenil pela Universidade Regional Integrada do Alto Uruguai e das Missões, URI. Especialista em Aprendizagens Psico-Lógicas na Universidade pelo Instituto Cenecista de Ensino Superior de Santo Ângelo, IESA. Graduada em Letras Português/Inglês e respectivas literaturas pela Universidade Integrada do Alto Uruguai e das Missões-URI. E-mail: maria.paranhos@iffarroupilha.edu.br

2Doutoranda em Educação nas Ciências pela Universidade Regional do Noroeste do Estado do Rio Grande do Sul - Unijuí, com Estágio de Doutoramento na Università di Bologna. Mestre em Educação nas Ciências pela Universidade Regional do Noroeste do Estado do Rio Grande do Sul - Unijuí, Especialista no Ensino de Geografia e da História pela Universidade Federal do Rio Grande do Sul - UFRGS. Graduada em História - Universidade Regional do Noroeste do Estado do Rio Grande do Sul - Unijuí.E-mail: claudia.ilgenfritz@hotmail.com ${ }^{3}$ Pós-doutoranda (PNPD-CAPES) no Programa de Pós-Graduação em Educação nas Ciências na Universidade Regional do Noroeste do Estado do Rio Grande do Sul - UNIJUí. Doutora e Mestre em Educação nas Ciências pela Universidade Regional do Noroeste do Estado do Rio Grande do Sul - UNIJUÍ. Graduada em Letras Português e respectiva Literatura pela Universidade Regional do Noroeste do Estado do Rio Grande do Sul UNIJUÍ. Licenciada em Pedagogia pela UNINTER.E-mail: marimmm1@hotmail.com 
components support for solving specific and complex problems that require understanding phenomena from different perspectives. In this context, it intensified contact with literary texts that address problematic sites, in relation to the universal. It led to appreciation of the art of theater recognizing such languages as mediators of knowledge of local history. Make up the corpus of this research questions answered by students of 3rd and 4th year of the course in Technical Agriculture of Instituto Federal de Ciência Educação e Tecnologia Farroupilha Campus Santo Augusto. This is a qualitative research. It was proposed questions about historical and social aspects of rural areas of the region so that students argumentassem about. There was the discursive analysis of these writings, based on Moraes \& Galliazzi (2012). The groups read, analyzed and discussed works of Rio Grande literature, watched the stage show "Quem faz gemer a terra" and were caused to write and discuss about. Taken up, then, the questions posed at the beginning of the research in order to analyze whether the subjects rebuilt the views of the historical and cultural aspects sites. It is evident that students have appropriated information, cultural issues rethought and expanded considerably skills in reading and writing.

Keywords: World Reading. Integrated Curriculum. Historical-Cultural Training.

\section{Introdução}

Este texto apresenta e busca refletir sobre uma proposta de Currículo Integrado com vistas à ampliação da formação histórico-cultural dos alunos do curso Técnico em Agropecuária do Instituto Federal de Ciência, Educação e Tecnologia Farroupilha (IFFar) Campus Santo Augusto. Tanto o município de Santo Augusto como os atendidos pelo IFFar possuem uma estrutura fundiária com base em latifúndios e, consequentemente, isso reflete nos movimentos sociais de luta pela terra.

$\mathrm{Na}$ atualidade, ainda há, de um lado, o modelo tradicional de ensino que se dá por meio do currículo formal, disciplinar, fragmentado; de outro, um currículo integrado que se fortalece a partir da Resolução 06/12 que define as Diretrizes Curriculares Nacionais para a Educação Profissional Técnica de Nível Médio no Brasil.

O modelo tradicional pode ser compreendido como um paradigma no qual o professor é o detentor do saber e ainda a principal fonte de informação. Assim, o ensino fundamenta-se na transmissão do saber do professor para os alunos, os projetos políticos pedagógicos e as aulas desenvolvidas são totalmente fragmentados (ARROYO, 2013). O currículo formal é dividido por disciplinas com campos de conhecimento específicos, delimitados e estanques, que devem ser esgotados por professores e alunos em prazos convencionalmente estabelecidos.

Por outro lado, a proposta do Currículo Integrado busca articular teoria e prática, o que torna o conhecimento integrado e interdisciplinar. Para tanto, faz-se necessária uma mobilização com uma ação docente integrada e coletiva, de forma a orientar as estratégias a 
serem utilizadas. Para Santomé (1998), o currículo integrado converte-se em uma categoria "guarda-chuva", agrupando uma variedade de práticas educacionais desenvolvidas em sala de aula.

O estudo aqui apresentado é uma pesquisa feita a partir desta proposta, que se debruça sobre ações pedagógicas desenvolvidas na perspectiva do Currículo Integrado, se organiza em torno de um problema que emerge na sala de aula em torno do Movimento dos Trabalhadores Sem-Terra $(\mathrm{MST})^{4}$. Os estudantes traziam ideias pré-concebidas, sem reconhecerem a problemática que atinge Santo Augusto e outras pequenas cidades da região, cujas periferias são formadas, essencialmente, por pessoas oriundas da zona rural. A partir da estruturação da pesquisa, os conteúdos das disciplinas de Língua Portuguesa e Literatura Brasileira auxiliaram na compreensão daquela realidade, interagiram dinamicamente, estabelecendo conexões e mediações.

O currículo integrado pode ser definido como um plano pedagógico e sua correspondente organização institucional articula dinamicamente trabalho e ensino, prática e teoria, ensino e comunidade. Tais relações entre os problemas e suas hipóteses de solução devem ter como pano de fundo as características socioculturais do meio em que o processo se desenvolve.

Uma forma de vivenciar o currículo integrado ocorre quando são trazidos exemplos da realidade para a reflexão dos discentes. No caso do ensino da Literatura e da Língua Portuguesa, no contexto desta pesquisa, foram apresentados autores e textos que traduziam a história, os conflitos próximos dos alunos para, a seguir, relacionar com um recorte da Literatura Rio-Grandense. O diferencial mais evidente é que o currículo integrado instiga o discente à reflexão e à significação do que aprende; enquanto o ensino tradicional apresenta, inicialmente, os conteúdos sem relação com o local e o social, o que cria barreiras ao desenvolvimento de um pensamento crítico sobre o assunto.

Dentre as justificativas para a realização deste estudo, estão a percepção, com a prática docente e com base em leituras, que existem fragilidades que podem ser apontadas do ensino tradicional através do currículo formal, como, por exemplo, a leitura de uma obra

${ }^{4} \mathrm{MST}$ - Movimento de caráter popular do qual participam trabalhadores oriundos do campo e que lutam pela Reforma Agrária. Movimento que iniciou na década de 1970 no Nordeste do Brasil. 
literária clássica e, ainda, o domínio da competência comunicativa (ARROYO, 2003). Além disso, a compreensão de contextos sócio-histórico-culturais constituintes da região, mas invisibilizados pelo currículo formal ou que não foram significados pelos alunos.

Competência comunicativa ou competência genérica, de acordo com Maingueneau (2000) é entendida como nossa aptidão para produzir e interpretar os enunciados de maneira adequada às múltiplas situações. Mas, o domínio da competência comunicativa não é suficiente para se participar de uma atividade verbal, outras duas instâncias intervêm na produção e interpretação dos enunciados: a competência linguística, que se refere ao domínio da língua e a competência enciclopédica, que diz respeito ao conhecimento de mundo.

A construção dessas três competências complementa-se na leitura de obras literárias, pela ampliação dos conhecimentos linguísticos, a ampliação do conhecimento de mundo e a interpretação dos enunciados em diferentes contextos de uso.

\section{Percurso metodológico}

O corpus dessa pesquisa foi composto por produções textuais, produzidas pelo grupo de alunos dos 3 e 4ำ anos do curso Técnico em Agropecuária, durante o ano letivo de 2014. Trata-se de uma pesquisa de caráter qualitativo que se desenvolveu em fases distintas. Inicialmente, foram propostas as seguintes questões sobre aspectos histórico-sociais do espaço rural da região para que os alunos argumentassem a respeito:

- Na sua opinião, por que existem Sem-Terras no Brasil?

- Qual é o papel do MST?

- Que motivos levam alguém a integrar o MST?

- Qual o perfil dos membros do MST.

- Por que acontece o êxodo rural?

- Na sua opinião, por que existem grandes proprietários de terras?

Tais questões possibilitaram que os alunos apresentassem seus conhecimentos acerca das transformações ocorridas no campo em decorrência do processo de 
industrialização e das políticas agrícolas de incentivo à monocultura; conflitos agrários; movimentos sociais; sujeitos sociais que participam de movimentos sociais agrários.

Foi feita Análise Textual Discursiva (ATD) dessas escritas, com base em Morais \& Galliazzi (2011). A ATD “corresponde a uma metodologia de análise de dados e informações de natureza qualitativa com a finalidade de produzir novas compreensões sobre os fenômenos e discursos" (MORAES \& GALLIAZZI, 2011, p. 7). Os grupos foram provocados à leitura, análise e discussão de aspectos estéticos de obras literárias da literatura riograndense que tratam das questões agrárias. Foram obras de Cyro Martins "Sem Rumo" (1937), "Porteira Fechada" (1993), "Estrada Nova" (1975); de Charles Kiefer: "O Pêndulo do Relógio" (1983) e "Quem faz gemer a terra" (1991). Os estudantes também assistiram ao espetáculo de teatro "Quem faz gemer a terra"5. A partir do espetáculo, produziram-se resenhas críticas, discussões, relações com outros gêneros textuais e artísticos, como a obra de Cândido Portinari.

Criou-se um blog "rumosdolerescrever.blogspot.com" com o objetivo não só de aproximar os alunos das tecnologias e significar esse uso em contextos de aprendizagem, mas também publicar as ações e os textos produzidos. Retornou-se, pois, à provocação das questões propostas no início da pesquisa a fim de analisar em que medida os sujeitos apropriaram-se de outras visões da história e cultura locais.

Focalizou-se o olhar sobre as categorias emergidas das escritas dos alunos acerca das experiências vivenciadas. São trazidos excertos das escritas para ilustrar a discussão. Os alunos participantes foram denominados pela inicial do seu pré-nome, preservando o sigilo dos participantes e, ao mesmo tempo, acompanhando a autoria de suas observações.

\section{Processo de formação histórico-cultural dos alunos: contribuições de um currículo integrado}

Inicialmente, convém pontuar a diferença visível entre as respostas escritas no questionário inicial e no final, não só em termos de argumentatividade, mas também na

${ }^{5}$ Criação do Grupo Teatral A Turma do Dionísio com texto adaptado da Obra Quem faz gemer a terra (KIEFER, 2006). O espetáculo foi encenado na escola. 
clareza das respostas. Além disso, houve dificuldade de analisar os questionários, pois muitas respostas eram incoerentes com a pergunta, ou apresentavam estruturas que impossibilitaram a construção de sentidos e revelavam a necessidade de um trabalho mais intenso de leitura e produção textual. Durante a aplicação dos questionários, houve alunos que perguntaram o significado de palavras como "latifundiário, êxodo rural, processo de modernização capitalista". Tais conceitos seguramente foram discutidos ao longo da formação desses alunos, porém não resultaram em conhecimento construído.

Serão apresentadas algumas categorias e excertos referentes às perguntas dos questionários respondidos pelos alunos no intuito de expor suas concepções antes e depois do trabalho realizado. Trata-se de uma tentativa de apresentar possibilidades de articulação entre as diferentes áreas do conhecimento e o currículo que pode ser visualizado. As categorias e os excertos a seguir evidenciam a visão dos alunos sobre a questão agrária na região, marcada por conflitos, onde se inicia o MST no RS. As escritas evidenciam um desconhecimento sobre a estrutura fundiária brasileira e sua origem histórica.

A partir do questionário inicial foram selecionadas três categorias: As grandes propriedades são resultado do trabalho e herança familiar; As grandes propriedades são resultado de esforço pessoal; Existência de Políticas favoráveis ao grande produtor. Com relação à primeira categoria que considera a presença de latifúndios no país como resultado de trabalho e herança familiar, os alunos escrevem que "Herdaram de seus pais e têm direito de ter as terras (V)" ou ainda, "O pai já era proprietário de grandes terras (E)".

\begin{tabular}{|l|l|}
\hline \multicolumn{1}{|c|}{ Categorias } & \multicolumn{1}{c|}{ Excertos } \\
\hline $\begin{array}{l}\text { As grandes propriedades são resultado do } \\
\text { trabalho e herança familiar }\end{array}$ & $\begin{array}{l}\text { Herdaram de seus pais e têm direito de ter as } \\
\text { terras }(\mathrm{V}) . \\
\text { O pai já era proprietário de grandes terras (E). }\end{array}$ \\
\hline O capital favorece a compra das terras & $\begin{array}{l}\text { Por ter mais poder em capital (AL). } \\
\text { Por terem mais produtividade, têm mais capital } \\
\text { e podem comprar mais terras (GU). } \\
\text { Facilidade de compra com menor preço em } \\
\text { grande quantidade (D). }\end{array}$ \\
\hline
\end{tabular}




\begin{tabular}{|c|c|}
\hline $\begin{array}{l}\text { As grandes propriedades são resultado de } \\
\text { esforço pessoal }\end{array}$ & $\begin{array}{l}\text { Acreditam no poder para crescer e acabam } \\
\text { crescendo }(A) \text {. } \\
\text { Conquista de terra por mérito próprio (R). } \\
\text { Querem a todo custo aumentar suas } \\
\text { propriedades (G). }\end{array}$ \\
\hline Políticas favoráveis ao grande produtor & $\begin{array}{l}\text { São proprietários que aproveitaram a época } \\
\text { fácil de aquisição de terras (D). } \\
{[\ldots] \text { a falta de incentivo ao pequeno }} \\
\text { proprietário no campo, a ilusão que nas } \\
\text { cidades há mais e melhores empregos (M). } \\
\text { Hoje em dia é aconselhado de certa forma a } \\
\text { plantar soja e milho e não se dá mais valor aos } \\
\text { pequenos monocultores (sic), então eles } \\
\text { largam a zona rural para ir para a hurbana (sic) } \\
\text { (CO). } \\
\text { Facilidade na compra com o menor preço em } \\
\text { grande quantidade (ALE). }\end{array}$ \\
\hline A pressão dos grandes proprietários & $\begin{array}{l}\text { A pressão dos grandes proprietários para a } \\
\text { venda das pequenas propriedades (SA). } \\
\text { Exploração dos pequenos agricultores que com } \\
\text { dificuldades econômicas acabam vendendo } \\
\text { suas terras (M). }\end{array}$ \\
\hline
\end{tabular}

Quadro 1. A Presença do Latifúndio na Região

Fonte: Elaborado pelas autoras a partir do questionário

Há evidências do desconhecimento das origens da agricultura latifundiária no país. A existência do latifúndio é entendida como sendo resultante do trabalho dos antepassados, esforço ou ambição pessoal. Isso pode ser visualizado ao analisar a categoria As grandes propriedades são resultado de esforço pessoal quando os alunos apontam que os latifúndios são resultado da "Conquista de terra por mérito próprio (G)"; "Acreditam no poder para crescer e acaba crescendo (D)"; "Querem a todo custo aumentar suas propriedades (V)". 


\begin{tabular}{|c|c|}
\hline Categorias & Excertos de textos \\
\hline A perda das terras & $\begin{array}{l}\text { É uma pessoa que perde seu lugar de morar e } \\
\text { sem ter pra onde ir junta-se aos outros do } \\
\text { movimento (CM). } \\
\text { Pessoas que perderam suas terras para o } \\
\text { governo e querem de volta (R). } \\
\text { Perderam suas terras para o governo ou para o } \\
\text { IBAMA (G). }\end{array}$ \\
\hline Aproveitadores do dinheiro público & $\begin{array}{l}\text { Muitos fazem parte para se aproveitar de } \\
\text { benefícios do governo (GU). } \\
\text { É uma pessoa que tem como objetivo receber } \\
\text { alguma ajuda do governo, desde rancho, } \\
\text { trabalhos, áreas de terra e salários, sem } \\
\text { trabalhar, ou seja, viver nas costas do governo } \\
\text { (E). }\end{array}$ \\
\hline Falta de conhecimento & Geralmente são agricultores analfabetos (S) \\
\hline Apropriação indevida & $\begin{array}{l}\text { Uma pessoa que busca terras para sua } \\
\text { sobrevivência retirando terras de quem é seu } \\
\text { legítimo dono (M). } \\
\text { Um cidadão que quer pegar as terras dos } \\
\text { outros, invadindo-as (A). } \\
\text { Eu acho errado, as pessoas lutaram para terem } \\
\text { o que têm e depois vem um grupo chega para } \\
\text { invadir a sua propriedade [...] eles querem } \\
\text { ganhar algo sem fazer esforço (V). }\end{array}$ \\
\hline
\end{tabular}




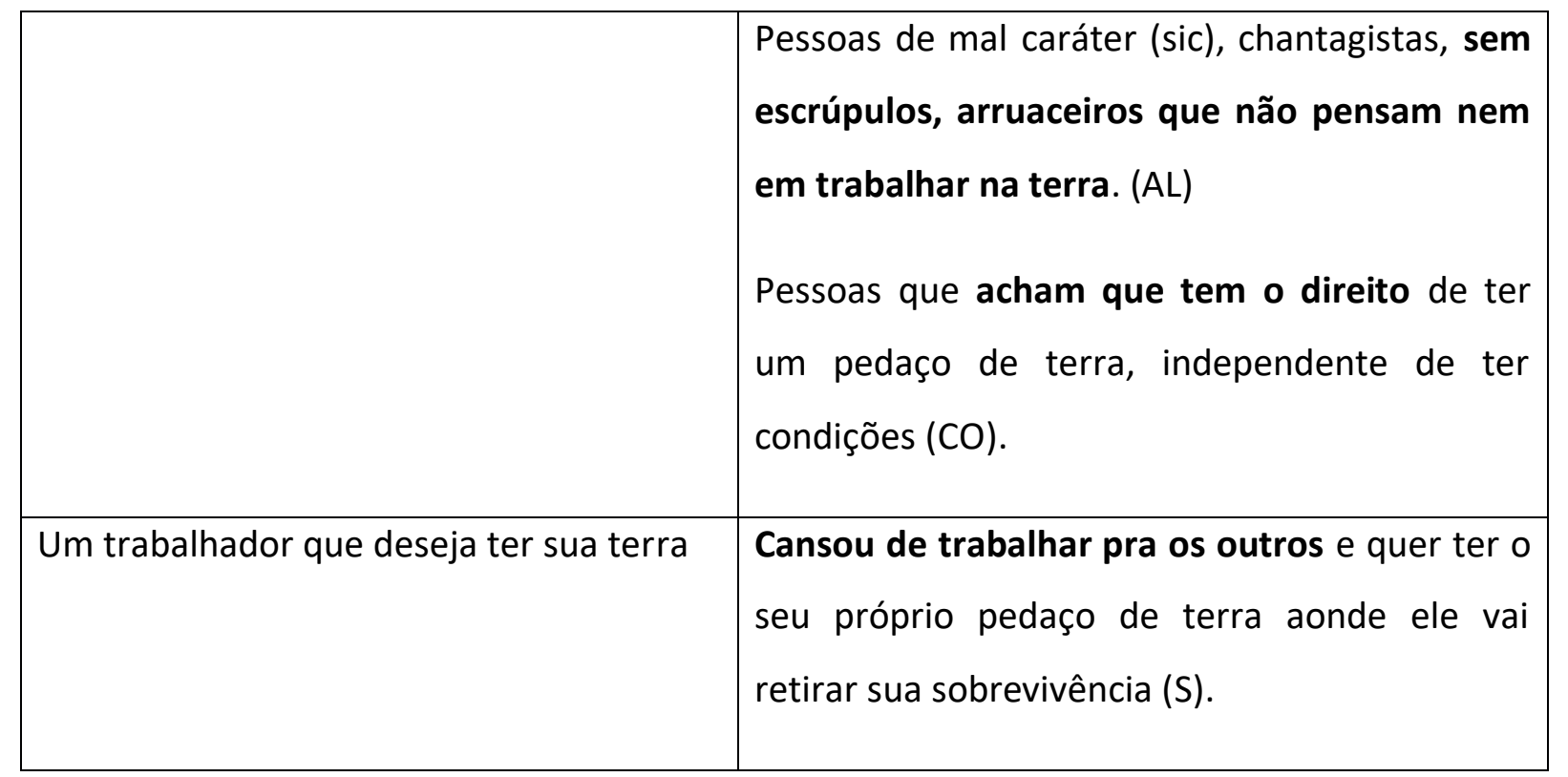

Quadro 2. A visão sobre os trabalhadores Sem-Terra Fonte: Elaboração das autoras a partir do questionário

Também, com relação aos trabalhadores Sem-Terra, revela-se uma visão preconceituosa. Convém considerar que 95\% desses alunos são filhos de minifundiários ou de ex-trabalhadores rurais que migraram para a cidade em busca de melhores condições de vida. Mesmo que esses conteúdos e conceitos tenham sido apresentados pela escola em diferentes tempos do processo de escolarização, é possível reconhecer discursos sustentados pelo senso comum. O currículo formal pode ter previsto esses conhecimentos e conceitos, mas a fragmentação e descontextualização da prática não possibilitaram a significação para a vida dos sujeitos.

Isso pode ser mais bem explicitado a partir das categorias e excertos com relação ao Perfil dos Participantes do MST. As categorias que emergiram foram: A perda das terras; Aproveitadores do dinheiro público; Falta de conhecimento; Apropriação indevida; Um trabalhador que deseja ter sua terra. É visível, nos excertos, o entendimento de forma simplificada e, até mesmo, preconceituosa no que diz respeito ao trabalhador sem-terra. 0 integrante do MST "perdeu a terra para o governo (GU)", "cansou de trabalhar para os outros (C)". Também a ideia preconceituosa, difundida na sociedade, de que são aproveitadores do governo: "Muitos fazem parte para se aproveitar de benefícios do governo" (GU). Além disso, há a percepção de que são pessoas "sem escrúpulos, 
arruaceiros que não pensam nem em trabalhar na terra(D)", ou ainda, "um cidadão que quer pegar as terras dos outros, invadindo-as" (E).

Tais excertos possibilitam, de observar que o discurso do senso comum predomina entre os alunos, os quais não se percebem como minifundiários. Ao longo do ano, o trabalho de leitura e escrita foi intensificado, com a exposição a diversos gêneros e linguagens, provocando-os ao debate crítico dos fatos que emergiam nesses contextos. Dentre as propostas desenvolvidas estão: estudos de textos jornalísticos, de letras de músicas e poemas. Além disso, ao longo do ano letivo foi feita a leitura e debate de contos, como "O Pêndulo do Relógio" (KIEFER, 1983), do romance Quem faz gemer a terra, também de Kiefer (1981); leitura e análise da Triologia Gaúcho a Pé, de Cyro Martins, composta pelos livros Porteira Fechada (1993), Sem Rumo (1937) e Estrada Nova (1975).

Então, lançou-se, novamente o questionário. A análise das escritas suscita três grandes temas a partir dos quais foi possível depreender as categorias apresentadas a seguir. Inicialmente, apresentamos as afirmações dos alunos sobre as mudanças conceituais sobre aspectos histórico-sociais, a partir das experiências vivenciadas. Num segundo momento, sobre as mudanças interpessoais $e$ intrapessoais e, por último, sobre a significação das aprendizagens e a função do docente como mediador dessas aprendizagens.

\begin{tabular}{|l|l|}
\hline \multicolumn{1}{|c|}{ Categorias } & \multicolumn{1}{|c|}{ Excertos de textos } \\
\hline Participante do MST & $\begin{array}{l}\text { Se integram nesse movimento aquelas pessoas que se } \\
\text { endividam e que são obrigadas a entregar seus bens para } \\
\text { poder quitar suas dívidas (ALE). } \\
\text { Por querer trabalhar com a monocultura se endividam } \\
\text { muito. O pequeno produtor precisa de técnicas e culturas } \\
\text { para a pequena propriedade (SA). } \\
\text { Pessoa com escolaridade baixa que não teve conhecimento } \\
\text { técnico necessário, muitas vezes, para manejar uma cultura } \\
\text { de grande escala, por exemplo, a soja, e se endivida (SA). } \\
\text { São pessoas que perdem tudo por uma escolha mal feita [...] } \\
\text { a necessidade de produzir sempre mais acabam acumulando } \\
\text { dívidas (V). }\end{array}$ \\
\hline
\end{tabular}




\begin{tabular}{|c|c|}
\hline & $\begin{array}{l}\text { A migração do pequeno proprietário rural para as cidades } \\
\text { acontece por passarem dificuldades nas propriedades. } \\
\text { Muitas dívidas nos bancos, pois precisam de empréstimos } \\
\text { para fazer o plantio e o manejo adequados (GU). } \\
\text { São pessoas que têm uma vida difícil. Uma pessoa que tem } \\
\text { vontade de ter sua própria terra e viver em cima dela, } \\
\text { tirando para sua sobrevivência }(V) \text {. }\end{array}$ \\
\hline $\begin{array}{l}\text { Políticas públicas para } 0 \\
\text { pequeno produtor }\end{array}$ & $\begin{array}{l}\text { As políticas públicas no país ao longo do tempo } \\
\text { incentivaram a monocultura (SA). } \\
\text { Muitos colonizadores chegaram e iam se apropriando das } \\
\text { terras, simplesmente, e expulsando os pequenos } \\
\text { proprietários. Em muitos casos aconteceu isso (EV). } \\
\text { Não houve governos que apresentassem políticas de } \\
\text { permanência do pequeno produtor no campo (EV). } \\
\text { Não ocorreu a tão esperada reforma agrária no país. Há os } \\
\text { Sem-Terra por não haver uma reforma agrária adequada no } \\
\text { país (D). }\end{array}$ \\
\hline $\begin{array}{l}\text { A monocultura foi um fator } \\
\text { que contribuiu para o êxodo } \\
\text { rural }\end{array}$ & $\begin{array}{l}\text { A relação entre o incentivo à monocultura e o êxodo rural é } \\
\text { que os pequenos produtores plantavam - e tem alguns que } \\
\text { ainda plantam- milho, feijão, arroz e com o incentivo à } \\
\text { monocultura acabaram plantando uma cultura só, a soja, o } \\
\text { que ocasionou a perda dessas propriedades por falta de } \\
\text { chuvas, ou seja, plantava a soja e dava a seca e não produzia } \\
\text { nada fazendo com que esses produtores vendessem suas } \\
\text { terras e fossem morar na cidade (CM). } \\
\text { Ainda não existem políticas públicas qualificadas para uma } \\
\text { diversificação de culturas e também a valorização do } \\
\text { homem do campo ... quanto mais incentivo à monocultura, } \\
\text { mais êxodo rural (D). } \\
\text { o governo ainda incentiva mais o plantio da soja e os }\end{array}$ \\
\hline
\end{tabular}


pequenos agricultores como não há muito recurso, acabam vendendo a propriedade e indo morar na cidade e trabalhar de empregado (M).

O mercado impõe ao produtor uma produção em grande escala, porém os pequenos produtores não dispõem de tecnologia para isso, então vendem suas terras para latifundiários e vão para as cidades, caracterizando assim o êxodo rural (G).

Onde há monocultura existe o latifúndio e quando isso ocorre o objetivo desse é só crescer comprando terras de pequenos agricultores que as vendem e vão para a cidade em busca de vida melhor (AM).

A mudança da agricultura familiar onde era produzido uma diversidade de produtos para a agricultura de monocultura. O uso de fertilizantes e produtos químicos e maquinários diminui a exigência de mão de obra. Também a introdução de equipamentos agrícolas fazendo com que uma ou duas pessoas na propriedade seja suficiente para realizar o serviço, aumentando o Êxodo rural (AC).

As políticas públicas que por muito tempo incentivaram a monocultura. As pessoas saem do campo com o objetivo de crescer na cidade, mas sem preparo caem na marginalidade (S).

Com as novas tecnologias, os grandes proprietários tiveram condições de melhorar sua produção e faltou auxílio ao pequeno produtor que precisava plantar suas áreas pedindo dinheiro emprestado, com um grande grau de risco $(E)$. Os grandes proprietários compram as terras de pequenos proprietários endividados ou sem motivação para ficar na 


\begin{tabular}{|l|l|l|}
\hline & $\begin{array}{l}\text { lavoura e sem conhecimentos técnicos para os cultivares } \\
\text { (G). } \\
\text { O governo disponibilizava financiamentos, a juros altos e } \\
\text { acabam não sendo pagos, levando o agricultor a grandes } \\
\text { dívidas impagáveis, fazendo com que o agricultor venda } \\
\text { suas terras e acabe indo morar na cidade (E). }\end{array}$ \\
\hline $\begin{array}{l}\text { As tecnologias e a a diminuição da demanda de } \\
\text { mão de obra }\end{array}$ & $\begin{array}{l}\text { Também a introdução de equipamentos agrícolas fazendo } \\
\text { com que uma ou dias pessoas na propriedade seja } \\
\text { suficiente para realizar o serviço, aumentando o êxodo } \\
\text { rural (AC). } \\
\text { Com o aumento das tecnologias, muitos grandes } \\
\text { proprietários cresceram ainda mais devido à facilidade de } \\
\text { lidar na lavoura, então os produtores acabaram vendendo } \\
\text { suas terras. Outro reflexo é que os pequenos produtores } \\
\text { trabalhavam de empregados e essa tecnologia veio e acabou } \\
\text { substituindo a mão de obra humana por máquinas (CM). }\end{array}$ \\
\hline
\end{tabular}

Quadro 3. Mudanças Conceituais

Fonte: Elaboração das autoras a partir do questionário

As categorias que emergem com relação às mudanças conceituais são: A presença de latifúndios é decorrência do êxodo rural e falta de conhecimento do pequeno agricultor; Participante do MST colonos que perderam suas terras por endividamento e falta de conhecimento; Ausência de políticas públicas para o pequeno produtor; A monocultura foi um fator que contribuiu para o êxodo rural; Financiamentos com juros altos.

O debate da questão agrária brasileira está intimamente ligado ao processo histórico de colonização do país. Inicia-se no período das capitanias hereditárias, passando pelos ciclos econômicos do açúcar, mineração, borracha, pecuária e café até os dias atuais, a questão da posse da terra esteve presente no cenário político brasileiro (MATTEI, 2005). De acordo com Tedesco e Carini (2010), desde a fundação do MST, as famílias participantes da ocupação têm se diferenciado. Na década de 1980, as famílias Sem-Terra participantes das ocupações eram predominantemente de origem rural. A partir da década de 1990, a participação de trabalhadores de origem urbana aumentou em decorrência da intensificação da mecanização da agricultura. 
A mudança conceitual quanto à presença de latifundiários e de trabalhadores rurais Sem-Terra foi bastante significativa. Um dos fatores mais apontados pelos alunos foi a falta de conhecimento dos agricultores para manejar as culturas que exigiam tecnologia, o que resultou no endividamento dos minifúndios. Essa constatação dos alunos embasa-se nas leituras das obras que relatavam casos fictícios de perdas de terra, tais como o de Guedes em “Porteira Fechada” (MARTINS, 1993).

Podemos perceber essa mudança conceitual em falas que se referem à presença de latifúndios como sendo decorrência do êxodo rural e falta de conhecimento do pequeno agricultor como "As pessoas saem do campo com o objetivo de crescer na cidade" (SA), ou ainda, "Com financiamentos surgiram dívidas devido ao mal estudo da proposta feita" (V). Antes do trabalho realizado, o entendimento sobre a presença dos latifúndios se sustentava unicamente na visão do senso comum, atribuída ao resultado do trabalho ou do esforço pessoal. Tais conflitos são tematizados na triologia Gaúcho a Pé, de Cyro Martins.

A importância do planejamento do professor e de sua concepção sobre que currículo deve ser considerado na escola e podem ser vistas na categoria Participante do MST, colonos que perderam suas terras por endividamento e falta de conhecimento, pois os alunos conseguem enxergar esses sujeitos como "[...] pessoa com escolaridade baixa que não teve conhecimento técnico necessário (...) e se endivida" (SA); ou que "[...] são pessoas que têm uma vida difícil. Uma pessoa que tem vontade de ter sua própria terra e viver em cima dela, tirando para sua sobrevivência" (V).

Já com relação ao grande tema, as mudanças interpessoais e intrapessoais emergiram as categorias: melhora na autoestima; ampliação do nível da linguagem; identificação com as personagens; ampliação do conhecimento de mundo e possibilidade de inovação de metodologias de ensino.

\begin{tabular}{|l|l|}
\hline \multicolumn{1}{|c|}{ Categorias } & \multicolumn{1}{|c|}{ Excertos de textos } \\
\hline Melhora na autoestima & $\begin{array}{l}\text { Esse projeto é a porta de entrada para um mundo de } \\
\text { cultura. Passamos por um árduo processo de escrita, } \\
\text { erramos, cansamos, reescrevemos, acertamos, } \\
\text { tivemos ajuda da nossa tutora, e depois disso, } \\
\text { deparamo-nos com a nossa escrita e vemos o quanto }\end{array}$ \\
\hline
\end{tabular}




\begin{tabular}{|c|c|}
\hline & $\begin{array}{l}\text { a aprimoramos (MA). } \\
\text { É com orgulho que digo que pude participar desse } \\
\text { projeto maravilhoso, aprender e forçar-me a } \\
\text { ultrapassar meus limites de escrita e com isso crescer } \\
\text { profissionalmente e socialmente (E). } \\
\text { A ideia de trazer o teatro, apresentar as obras e criar o } \\
\text { blog Rumos do ler e escrever foi maravilhosa, pois é } \\
\text { algo muito especial para os alunos do } 3^{\circ} \text { e } 4^{\circ} \text { ano do } \\
\text { curso Técnico Agropecuária (S). } \\
\text { É muito gratificante poder ver nesse blog os bons } \\
\text { resultados que essa bela iniciativa que a Professora nos } \\
\text { proporcionou com todas as atividades (MO). }\end{array}$ \\
\hline Identificação com as personagens & $\begin{array}{l}\text { Dessa forma com todas as atividades que nos foram } \\
\text { propostas como os filmes, os livros, o teatro, os belos } \\
\text { textos que sempre nos foram trazidos, tivemos } \\
\text { novidades. Essas metodologias sempre nos trouxeram } \\
\text { algum ponto de vista que nos identificava com as } \\
\text { obras. Assim podemos com a vontade e a } \\
\text { perseverança de todos evoluir e hoje ser mais } \\
\text { completos com a escrita e a forma de interpretar } \\
\text { melhor o mundo ao nosso redor (MO). } \\
\text { O teatro é uma oportunidade de agregarmos } \\
\text { conhecimento e cultura de diversas áreas diferentes } \\
\text { das que estamos acostumados, porém mantendo a } \\
\text { mesma cultura que nos originou e nos caracteriza } \\
\text { (MA). } \\
\text { É um espetáculo [...] capaz de nos fazer entrar na } \\
\text { história e nos emocionarmos com a angústia que a } \\
\text { história representa. Além de certa relação com nossa } \\
\text { realidade, pois muitas de nossas famílias são vítimas }\end{array}$ \\
\hline
\end{tabular}




\begin{tabular}{|c|c|}
\hline & $\begin{array}{l}\text { dessa mesma situação de perda de terra aos bancos } \\
\text { por causa de dívidas e de falta de conhecimento (CO). }\end{array}$ \\
\hline $\begin{array}{l}\text { Ampliação do conhecimento de } \\
\text { mundo }\end{array}$ & $\begin{array}{l}\text { O blog Rumos do Ler e Escrever, nos traz várias } \\
\text { experiências, pois, compõe-se de várias histórias do } \\
\text { viver, de diferentes pessoas, de lugares diferentes (D). }\end{array}$ \\
\hline $\begin{array}{l}\text { Ampliação da competência } \\
\text { comunicativa }\end{array}$ & $\begin{array}{l}\text { O ler e o escrever durante esse ano não foi muito fácil, } \\
\text { pois a professora nos exigiu muito, fazendo com que } \\
\text { nós aprendêssemos a escrever os textos certo, e como } \\
\text { interpretar os textos, nos ajudando para saber como } \\
\text { se expressar (AP). } \\
\text { Trabalho ajudou os alunos do Técnico em } \\
\text { Agropecuária, a escrever cada vez mais e melhor. } \\
\text { Estes alunos, na maioria das vezes, não se interessam } \\
\text { muito por esta área, pois vêm da área agrícola, uma } \\
\text { área onde convivem mais com o trabalho braçal e não } \\
\text { utilizam tanto da sua capacidade mental muitas vezes } \\
\text { por não acreditarem na sua habilidade (LP). } \\
\text { [...] através dele podemos compartilhar e desfrutar de } \\
\text { conhecimento e leitura. Além disso, estamos } \\
\text { ampliando nosso vocabulário cada vez mais (D). } \\
\text { Esse trabalho veio para nós como uma grande } \\
\text { oportunidade de nos expressarmos mais ainda, } \\
\text { motivando-nos a cada leitura, fazendo uma análise de } \\
\text { ideais sejam divulgados para muitas pessoas que têm a } \\
\text { leitura como uma porta para novos conhecimentos }\end{array}$ \\
\hline
\end{tabular}




\begin{tabular}{|c|c|}
\hline & $\begin{array}{l}\text { (M). } \\
\text { Garanto que apesar das dificuldades, tudo isso foi } \\
\text { muito proveitoso para o desempenho da disciplina e } \\
\text { para a cada um de nós!!! } \\
\text { A professora que nos incentiva todos os dias que nos } \\
\text { encontramos, nos motiva a escrever, vencendo nossos } \\
\text { próprios limites e ultrapassando as barreiras } \\
\text { encontradas nos caminhos da leitura e da escrita (A). } \\
\text { Essa nova forma implantada para postar os textos é } \\
\text { interessante, pois os alunos se sentem intimados a } \\
\text { melhorar seus textos, para serem postados no blog. } \\
\text { Dando assim um maior conhecimento ao aluno, } \\
\text { fazendo com que ele não sinta medo de enfrentar } \\
\text { uma redação de vestibular, uma entrevista de } \\
\text { emprego. Tornando-o capacitado para uma vaga de } \\
\text { trabalho em uma empresa de grande porte no futuro } \\
\text { (AC). } \\
\text { grande conhecimento, talvez pelo fato de escrevermos } \\
\text { e reescrevermos eles várias vezes até estarem de boa } \\
\text { clareza e entendimento (G). }\end{array}$ \\
\hline $\begin{array}{l}\text { Possibilidade de inovação de } \\
\text { metodologias de ensino }\end{array}$ & $\begin{array}{l}\text { Devido a este projeto, tivemos a oportunidade de } \\
\text { assistir a teatros, ver filme, ler alguns livros e } \\
\text { conhecer histórias com as quais nunca tínhamos nos } \\
\text { deparado (GU). } \\
\text { Os textos foram bem desenvolvidos com o auxílio de } \\
\text { diversos métodos empregados, os quais faziam com } \\
\text { que houvesse uma interação com os colegas, }\end{array}$ \\
\hline
\end{tabular}




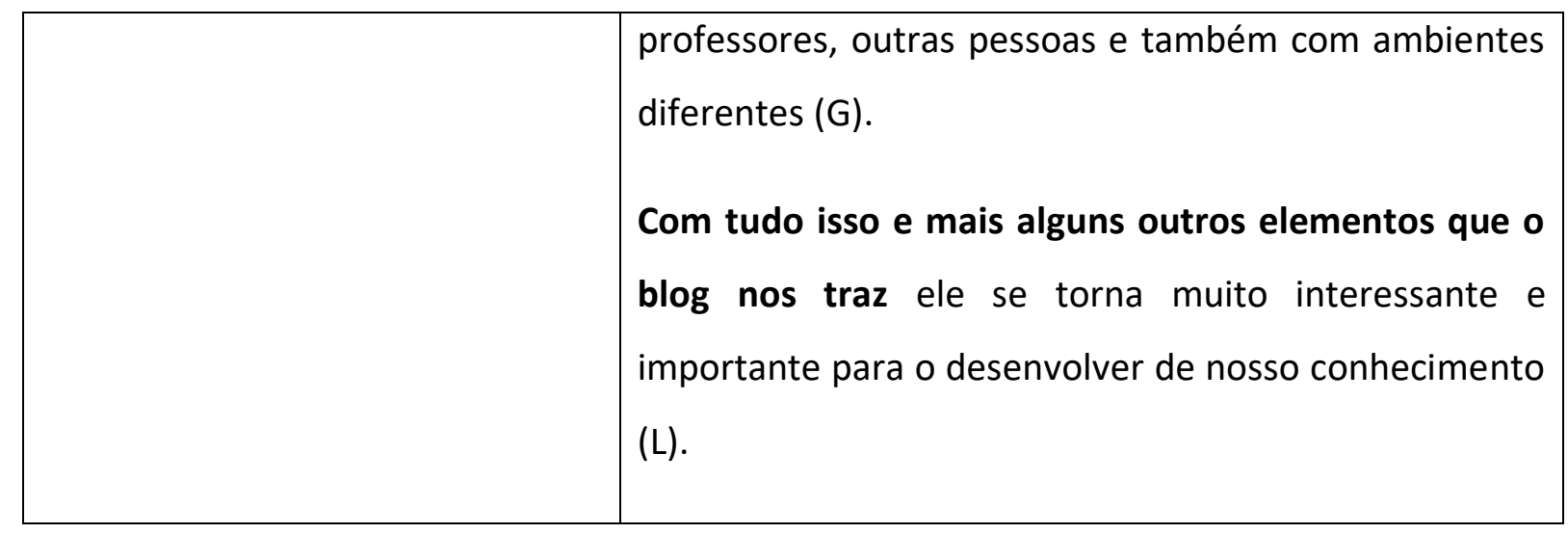

Quadro 4. Mudanças Interpessoais e Intrapessoais

Fonte: Elaboração das autoras a partir do questionário

Ao visualizar os excertos é possível reconhecer a ampliação da visão de mundo desses sujeitos, principalmente por realizar um trabalho com vistas a complexificar o processo de análise e construção do conhecimento. Ao considerar as concepções prévias dos alunos, se redimensiona o trabalho criando estratégias para que estas sejam colocadas em xeque. Quando o currículo não é mais fechado e estanque, a possibilidade de dar significado tanto ao que o aluno já conhece quanto ao que vai construindo é impossível de ser quantificado.

E os alunos reconhecem isso, como é o caso de $\mathrm{MO}$ quando se refere à identificação com os personagens das histórias lidas. Diz ele que "[...] todas as atividades que nos foram propostas como os filmes, os livros, o teatro, os belos textos que sempre nos foram trazidos, tivemos novidades. Essas metodologias sempre nos trouxeram algum ponto de vista que nos identificava com as obras. Assim podemos com a vontade e a perseverança de todos evoluir e hoje ser mais completos com a escrita e a forma de interpretar melhor o mundo ao nosso redor".

O excerto da fala do aluno nos remete aos estudos de Vigotski (2007) que indicam para a essencialidade da mediação e da interação na construção do conhecimento. 0 professor, com o conteúdo e metodologias, e o aluno, que processa as informações tendo como ponto de partida sua cultura, seus conhecimentos para construir sentidos sobre o que está sendo estudado. Com isso, o aluno, em um processo inicialmente interpessoal, depois intrapessoal, capta e interioriza a informação, reconstrói e atribui sentidos às informações a partir de experiências anteriores, gerando para si novos conhecimentos. 
Peralta (2004) pontua sobre os limites construídos para as áreas do conhecimento e para as disciplinas curriculares. Explica que a criação humana transita entre as áreas do conhecimento e das disciplinas convencionais, desconhecendo seus limites. A prática transdisciplinar pode conduzir a campos inusitados do saber e possibilitar a significação de conceitos, atribuições de novos sentidos o contexto agrário, possibilitados a partir do teatro e da literatura, assim como mudanças de paradigmas, conforme ilustram as escritas dos alunos apresentadas aqui.

Foi significativa a ampliação da competência comunicativa dos alunos. Essa mudança evidencia-se tanto no nível dos textos produzidos e das discussões desenvolvidas nas aulas quanto no engajamento com as propostas de produção escrita. AP manifesta a percepção da complexidade dos processos: “[...] ler e o escrever durante esse ano não foi muito fácil, pois a professora nos exigiu muito, fazendo com que nós aprendêssemos a escrever os textos certos, e como interpretar os textos, nos ajudando para saber como se expressar. D, por sua vez, defende que, através desse trabalho, "podemos compartilhar e desfrutar de conhecimento e leitura. Além disso, estamos ampliando nosso vocabulário cada vez mais. Também reconhecem: "esse trabalho veio para nós como uma grande oportunidade de nos expressarmos mais ainda, motivando-nos a cada leitura, fazendo uma análise de todos os aspectos envolvidos nos materiais lidos. Ou seja, permitindo que nossos trabalhos, pensamentos, ideais sejam divulgados para muitas pessoas que têm a leitura como uma porta para novos conhecimentos" (M).

O pensamento de Paulo Freire contribui com esse processo, pois apresenta uma crítica radical a um modelo de educação baseado na reprodução social de cunho autoritário e dominador. Ler o mundo, para Freire, é criar e recriar cultura. Nas palavras do pedagogo "O analfabeto apreende criticamente a necessidade de aprender a ler e a escrever. Preparase para ser o agente desta aprendizagem" (FREIRE, 1981, p.72). Freire acreditava que a educação deve cumprir a tarefa de propiciar aos homens condições de desenvolvimento de sua consciência e leitura crítica do mundo, incentivando intervenções e ações no sentido da libertação. Freire defendia também que as ações entre educador e educando deveriam priorizar o aprofundamento do conhecimento e a leitura crítica do mundo, numa permanente construção e apreensão da realidade com vistas à construção de uma consciência crítica. 


\section{Conclusões}

O envolvimento dos alunos na proposta, inserindo-se nas discussões, estabelecendo relações e significando as leituras e escritas contribuiu para o aprimoramento das habilidades de leitura e expressão em especial a escrita. Foram muitas as atividades de escrita e reescrita de textos, o que conferiu seriedade à tarefa. Entenderam a necessidade de o texto ser visto como um processo, em constante reconstrução e não como um produto acabado. Desenvolver a criticidade diante das próprias escritas e desejar melhorar seu desempenho foi uma das importantes aprendizagens ao longo do projeto.

A presença de diferentes linguagens, como do cinema, da literatura, da música, do teatro, não só possibilitou esse olhar mais amplo, como também tornou os encontros provocadores e possibilitadores de novas visões diante dos fatos. $\mathrm{O}$ aprimoramento do conhecimento desses jovens deu-se tanto no que diz respeito às questões conceituais potencializadas na pesquisa quanto no desenvolvimento das competências de ler e escrever. O nível de leitura e escrita dos alunos que ingressam do Curso Técnico em Agropecuária é precário. Isso precisa ser visto como um desafio a ser enfrentado, ao contrário, continuará como um dado a mais o número de reprovações e evasões.

A obra de Charles Kiefer e de Cyro Martins retrata com lucidez uma sociedade rural em constante tensão, conhecida da realidade daqueles alunos, mas negada em seus discursos antes da experiência literária e teatral. Essas obras possibilitaram ir além. Pelo seu caráter universal, introduzem questões referentes à natureza humana, na partilha das dores e alegrias de ser. Como os jovens estudantes dos cursos técnicos, as personagens ambicionam uma sociedade mais justa e igualitária e as obras operaram em favor do processo de formação desses alunos.

A pesquisa possibilitou superar a estrutura linear e fragmentada dos conteúdos disciplinares por meio da interlocução com diferentes disciplinas para propiciar a produção de um currículo integrado que prioriza o estudo dos conteúdos escolares situados em contextos de relevância social e de vivência cotidiana dos estudantes. Assim, produzem sentidos e significados para eles e articulam teoria e prática pelo uso dos recursos culturais linguagem, leitura e escrita. 


\section{REFERÊNCIAS}

ARROYO, M. G. Currículo, território em disputa. Petrópolis: Vozes, 2013.

BRASIL. Ministério da Educação. Conselho Nacional de Educação. Câmara da Educação Básica. Parecer CNE/CEB no 11, de 09 de maio de 2012. Diretrizes Curriculares Nacionais para a Educação Profissional Técnica de Nível Médio. Brasília, DF: 09 de maio de 2012.

FREIRE, P. Educação e Mudança. Rio de Janeiro: Paz e Terra, 1981.KIEFER, C. O pêndulo do relógio. Porto Alegre: Amarilys, 1983.

. Quem faz gemer a terra. São Paulo: Record, 1991.

MAINGUENEAU, D. Análise de Textos de Comunicação. São Paulo: Cortez, 2001.

MARTINS, C. Estrada nova. Porto Alegre: Movimento, 1975.

. Porteira fechada. Porto Alegre: Movimento, 1993.

. Sem rumo. Rio de Janeiro: Ariel, 1937.

MATTEI, L. Reforma Agrária e programas de assentamento rurais: o dilema atual da questão agrária brasileira. Porto Alegre: Artes Médicas Sul, 1998.

MORAIS R. \& GALLIAZZI H. Análise textual discursiva. Ijuí: Ed. Unijuí, 2011.

PERALTA, C. H. G. Transdisciplinaridade e confluências em Artes, Filosofia e Educação Básica: da subjetividade criadora à criação de realidades. In: Ensino de artes: múltiplos olhares. CORRÊA, A. D. Ijuí: Ed Unijuí, 2004.

SANTOMÉ, J. T. Globalização e interdisciplinaridade: o currículo integrado. Porto Alegre: Artes Médicas Sul; 1998.

TEDESCO, J. C; CARINI, Joel. J.(Orgs.). Conflitos agrários no norte gaúcho, v. III. 1. ed. Passo Fundo/RS: Editora Imed, 2010.

VIGOTSKI, L. A formação social da mente. São Paulo: Martins Fontes, 2007.

Data de submissão: 30/09/2017. Data de aprovação: 13/11/2017. 
